\title{
A prospective observational cohort study of posterior tibial nerve stimulation in patients with multiple sclerosis: design and methods
}

Giulia I. Lane ${ }^{1 *} \mathbb{D}$, Yang Mao-Draayer ${ }^{2}$, Paholo Barboglio-Romo ${ }^{1}$, J. Quentin Clemens', Priyanka Gupta', Rod Dunn', Yongmei Qin ${ }^{1}$, Anne P. Cameron ${ }^{1}$ and John T. Stoffel ${ }^{1}$

\begin{abstract}
Background: Posterior tibial nerve stimulation (PTNS) is a promising treatment for lower urinary tract symptoms (LUTS) in patients with MS. However, long term data focusing on PTNS impact on health-related quality of life (HRQOL), bowel and bladder symptoms are lacking. This paper describes a study protocol that examines the extended efficacy of PTNS on MS related bladder and bowel symptoms and resulting HRQOL.

Methods/Design: This is a single-centered, prospective, longitudinal, observational cohort study of patients with MS who suffer from LUTS and are refractory to two prior treatment modalities. Participants who have elected to pursue PTNS therapy for LUTS will be eligible. The primary outcome is the median number of urinary frequency and incontinence episodes on a 3-day voiding diary at 3,12 and 24 months compared to baseline. Secondary outcome measures will include change in total AUA-SS, M-ISI, NBSS, SF-12, SSS and BCS scores from baseline The Expanded Disability Status Scale and magnetic resonance imaging will be evaluated at baseline and annually throughout the study.

Discussion: This research protocol aims to expand on the existing literature regarding outcomes of PTNS in MS. Specifically, it will provide long term follow-up data on bladder, bowel, sexual and HRQOL outcomes. The completion of this study will provide longitudinal efficacy data of the impact of PTNS in MS patients.
\end{abstract}

Trial registration: NCT04063852.

Keywords: Quality of life, Urinary incontinence, Neuromodulation, Multiple sclerosis, Prospective studies, Tibial nerve, Urinary bladder, Neurogenic

\section{Background}

Multiple Sclerosis (MS) is the most common autoimmune neuro-inflammatory disease of the central nervous system and affects approximately 31 per 100,000

\footnotetext{
* Correspondence: giuliala@med.umich.edu

'Department of Urology, University of Michigan, 1500 East Medical Drive, Taubman Center 3875, Ann Arbor, Ml 48109, USA

Full list of author information is available at the end of the article
}

Americans annually, with 700,000 Americans living with MS in 2010 [1].

MS is characterized by four primary disease courses: clinically isolated syndrome (CIS), relapsing remitting (RRMS), secondary progressive (SPMS) and primary progressive (PPMS) [2,3]. Clinically isolated syndrome is a pre-MS syndrome and is described as the initial episode of neurologic deficit which may progress to MS. [2] In some patients, CIS precedes the diagnosis of relapsing-remitting

C C The Author(s). 2020 Open Access This article is licensed under a Creative Commons Attribution 4.0 International License, which permits use, sharing, adaptation, distribution and reproduction in any medium or format, as long as you give appropriate credit to the original author(s) and the source, provide a link to the Creative Commons licence, and indicate if changes were made. The images or other third party material in this article are included in the article's Creative Commons licence, unless indicated otherwise in a credit line to the material. If material is not included in the article's Creative Commons licence and your intended use is not permitted by statutory regulation or exceeds the permitted use, you will need to obtain permission directly from the copyright holder. To view a copy of this licence, visit http://creativecommons.org/licenses/by/4.0/ The Creative Commons Public Domain Dedication waiver (http://creativecommons.org/publicdomain/zero/1.0/) applies to the data made available in this article, unless otherwise stated in a credit line to the data. 
MS (RR-MS). Relapsing-remitting MS (RRMS) is characterized by discrete episodes of neurological dysfunction or relapses, with no interim disease progression. Patients may fully recover from a relapse or may experience residual deficits. Secondary progressive MS patients have gradual neurological deterioration (progression) with increasing physical debilitation following a period of relapsing remitting disease [4]. Finally, primary-progressive MS (PPMS) is defined as steady disease progression from its onset and may include periods of stable disease or temporary symptomatic improvement [5].

Lower urinary symptoms (LUTS) including overactive bladder $(\mathrm{OAB})$ are reported in $75-90 \%$ of all MS patients, and can be very bothersome to patients [6]. However, stage and type of disease may impact perception and severity of urinary symptoms in MS patients. Utilizing urodynamic data, others showed that there is high prevalence of urinary symptoms even in clinically isolated syndrome (CIS), before greater neurologic impact from the disease is found [7]. Once patients have established disease, urinary symptoms may be perceived differently based on rapidity of disease progress.

Current management of MS related LUTS follows the overactive bladder pathway: first line lifestyle modifications, second line adjunctive pharmacotherapy, third line neuromodulation (sacral or posterior tibial) or chemodenervation of the bladder (onabotulinum toxin) and fourth line invasive surgical reconstruction [8-10]. The implementation of intermittent or indwelling catheter can be an adjunct to these therapies (Fig. 1).
Each intervention can have significant quality of life implications. For example, second line pharmacotherapy with anticholinergic is often poorly tolerated because it can exacerbate symptoms of dry mouth, constipation and central nervous system side effects like confusion [8]. Likewise, the addition of intermittent catheterization can add complexity to the patient's lifestyle with unclear impact on decreasing LUTS [11]. In regards to third line therapy, intradetrusor onabotulinumtoxin (Botox) can be effective at controlling symptoms, but it requires cystoscopy to administer, the treatment needs to be repeated every 6-12 months, and each administration carries a risk of urinary tract infection and urinary retention [12].

Neuromodulation, another third line therapy, includes both sacral neuromodulation and posterior tibial nerve stimulation. Sacral neuromodulation involves 1 or 2 surgeries for placement of a neuromodulation lead and an implantable pulse generator to stimulate the S3 nerve root. Limited data suggest sacral neuromodulation may be effective for MS related LUTS, however the sacral neuromodulation leads are not MRI compatible $[8,13,14]$. Since many patients with MS require frequent MRI for surveillance, this poses a barrier for use of current implantable sacral neuromodulation technology. In these patients, percutaneous posterior tibial nerve stimulation (PTNS) offers a minimally invasive alternative to relieve bladder symptoms via similar pathways as sacral neuromodulation.

Posterior tibial nerve stimulation, involves placement of a solid stainless-steel needle into the posterior tibial

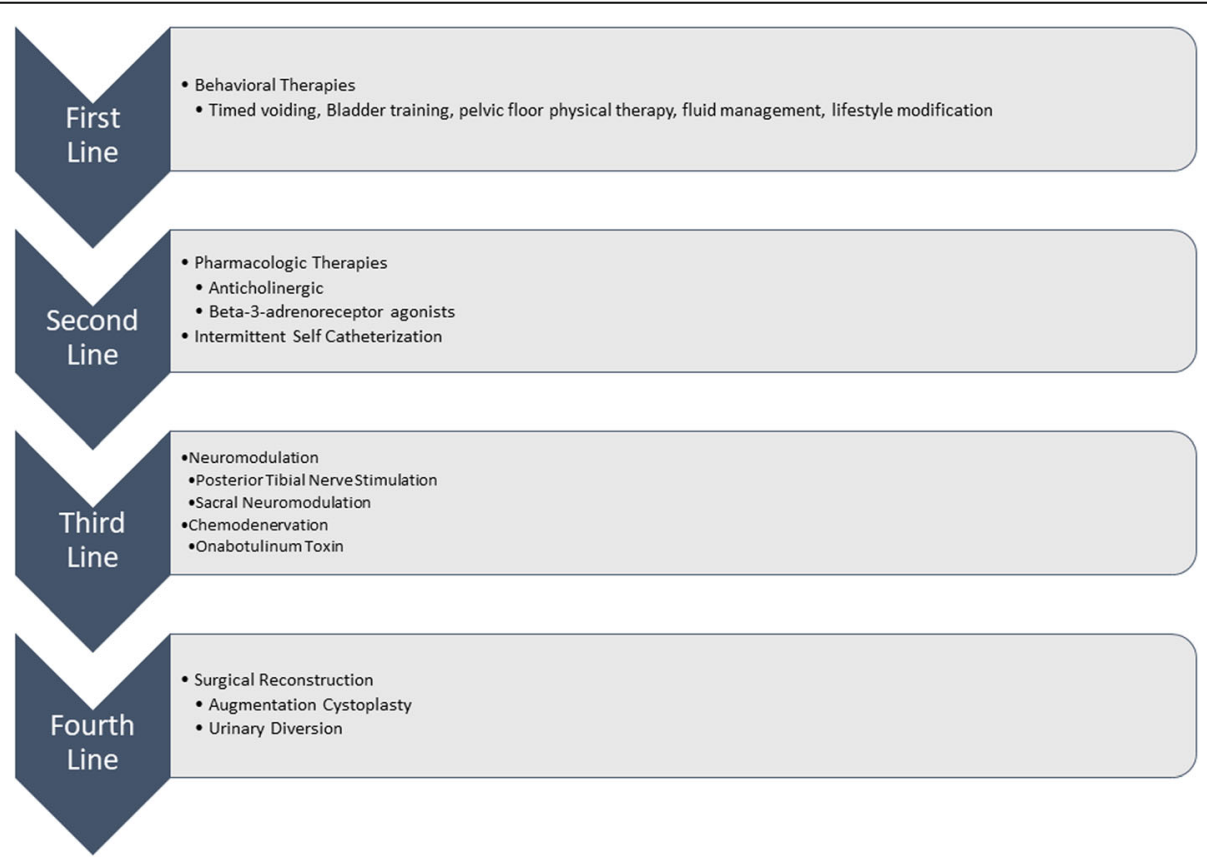

Fig. 1 Management of Lower Urinary Tract Symptoms in Patients with Multiple Sclerosis 
nerve and uses this to conduct a fixed electrical pulse through the nerve. The posterior tibial nerve derives from the L4-S3 nerve roots, neuromodulation of this nerve has been shown to improve overactive bladder symptoms [15]. The office-based therapy is performed weekly for 12 weeks during 30-min sessions; patients who have improvement in symptoms can proceed to maintenance treatments at regularly scheduled intervals.

Only seven clinical studies have been published regarding the use of PTNS in patients with MS and refractory LUTS [16-22]. (Table 1) Of these studies, four represent prospective case series evaluating the efficacy of PTNS for LUTS in MS, with a total of 131 patients $[18-20,22]$. These studies reported significant improvement in LUTS with overall the rate of improvement (defined as greater than $50 \%$ improvement in symptoms) between 33 and $89 \%$ (Table 1).

Despite these findings, the studies were limited by their short term follow up (range 3-12 months), strict inclusion criteria, and lack of important quality of life outcomes. Outcomes beyond 12 months and the impact of standard maintenance therapy have only been studied in one prior study [20]. Moreover, there is limited research on the effects of PTNS on related pelvic organ dysfunction such as bowel and sexual function among patients with MS. [23, 24] As PTNS requires significant investment on the part of patients and clinicians, further studies generating more robust evidence regarding the long term impact of this therapy are warranted. Furthermore, we believe it is important to follow PTNS treatment outcomes longitudinally to determine if it is effective in a progressive disease such as MS. Previous published PTNS studies did not address how efficacy could be affected by the type of MS, disability status or whether the efficacy could be maintained long term in the setting of a progressive disease.

Therefore, the aim of this study is to describe shortand long-term clinical outcomes, including quality of life, bladder, bowel and sexual function, in MS patients who undergo PTNS treatment for refractory LUTS.

Table 1 Literature review of Posterior Tibial Nerve Stimulation in Multiple Sclerosis

\begin{tabular}{|c|c|c|c|c|c|}
\hline Author & Year & $\mathrm{N}$ & Inclusion Criteria* & $\begin{array}{l}\text { Follow-up } \\
\text { (months) }\end{array}$ & Primary Outcome Results \\
\hline $\begin{array}{l}\text { Fjorback } \\
\text { [1] }\end{array}$ & '07 & 8 & $\begin{array}{l}\text { UDS: DO and MCC < } \\
300 \mathrm{~mL}\end{array}$ & $\mathrm{n} / \mathrm{a}$ & $\begin{array}{l}\text { - PTNS unable to suppress detrusor contraction. } \\
\text { - No reduction of urgency } \\
\text { - No difference in peak detrusor pressure } \\
\text { - Median volume at first contraction was } 36 \% \text { higher with stimulation. }(p=0.0078)\end{array}$ \\
\hline Kabay [2] & ’08 & 29 & storage symptoms & $\mathrm{n} / \mathrm{a}$ & $\begin{array}{l}\text { - Mean volume first involuntary contraction increased from } 183 \text { to } 230 \mathrm{~mL} \text {. }(p< \\
\text { - Mean) } \\
\text { - Mean maximum cystometric capacity increased from } 193 \text { to } 286 \mathrm{~mL} \text {. }(p<0.001)\end{array}$ \\
\hline Kabay [3] & '09 & 19 & LUTS & 3 & $\begin{array}{l}\text { - Complete Response rates > 50\% improvement: urgency }(33 \%) \text {, incontinence } \\
\text { ( } 40 \%) \text {, frequency }(58 \%) \text {, nocturia }(75 \%) \text {, pad test }(90 \%) \text { of patients } \\
\text { - Partial Response between } 25 \text { and } 50 \% \text { improvement:urgency }(53 \%) \text {, incontinence } \\
(50 \%) \text {, frequency }(26 \%) \text {, nocturia }(25 \%) \text {, pad test }(10 \%) \text { of patients } \\
\text { - UDS response: DSD resolved in 3/5, significant improvement after PTNS in first } \\
\text { involuntary detrusor contraction volume, MCC, Qmax, PVR }(p<0.05)\end{array}$ \\
\hline $\begin{array}{l}\text { de Seze } \\
{[4]^{* *}}\end{array}$ & $' 11$ & 70 & $\begin{array}{l}\text { refractory } O A B \\
\text { symptoms }\end{array}$ & 3 & $\begin{array}{l}\text { - } 30 \mathrm{~d} \text { : } 51 \% \text { resolution of severe urgency, } 67 \% \text { reduction in frequency by } 3 \\
\text { episodes/day } \\
\text { - } 90 \mathrm{~d} \text { : improvement in } 83.3 \% \text { of patients in } 3 \text { day bladder diary, MHU or warning } \\
\text { time }\end{array}$ \\
\hline Gobbi [5] & $' 11$ & 18 & refractory LUTS & 3 & $\begin{array}{l}\text { - Improved frequency, nocturia, Increased voided volume, } \\
\text { - PPBC decreased by } 3 \text { points }(p=0.003) \text {, PPIUS decreased by } 2 \text { points }(p=0.005) \text {, } \\
\text { UB-VAS decreased by } 4 \mathrm{~cm}(p=0.005) \text {, improvement in KHQ }(p<0.05)\end{array}$ \\
\hline Zecca [6] & $' 14$ & $\begin{array}{l}\text { initial: } \\
83 \\
\text { Maint: } \\
74\end{array}$ & $\begin{array}{l}\text { refractory LUTS, UDS } \\
\text { with DO, UAB or DSD }\end{array}$ & 24 & $\begin{array}{l}\text { - } 60 \% \text { (44/74) required maintenance every } 2 \text { weeks, } 4 \% \text { required maintenance } \\
\text { every week, mean treatment was: } 1.79 \text { sessions/patient/month } \\
\text { - } 82 \% \text { of patients reported treatment satisfaction on TS-VAS, GRA, and PPBC at } 24 \\
\text { months }\end{array}$ \\
\hline Zecca [7] & $' 14$ & 83 & $\begin{array}{l}\text { refractory LUTS, UDS } \\
\text { with Dom UAB or DSD }\end{array}$ & 3 & $\begin{array}{l}\text { - Sensory response: } 64 \% \text {, Motor response: } 6 \% \text {, Sensory-Motor: } 30 \% \text {; } \\
\text { Sensory response with or without motor response was associated with better } \\
\text { outcome than motor alone }(p<0.001)\end{array}$ \\
\hline $\begin{array}{l}\text { Canbaz- } \\
\text { Kabay [23] }\end{array}$ & $' 17$ & $\begin{array}{l}\text { initial: } \\
29 \\
\text { Maint: } \\
21\end{array}$ & refractory $O A B$ & 12 & $\begin{array}{l}\text { - Improvement in frequency, nocturia, urgency (all } p<0.001) \text { and voided volume } \\
\text { improved mean } 72 \mathrm{cc}(p<0.05) \text {. } \\
\text { - Change from baseline on the ICIQ-SF, OABv8 and OAB-q: decreased symptom se- } \\
\text { verity and health related quality of life }(P<0.001)\end{array}$ \\
\hline
\end{tabular}

*all studies included adults with multiple sclerosis

* Study of Transcutaneous PTNS versus others, which were percutaneous

UDS urodynamics, DO detrusor overactivity, MCC Maximum Cystometric Capacity, LUTS Lower urinary tract symptoms, Maint Maintenance, NR Not reported 


\section{Methods/Design}

\section{Study design and population}

The study is registered with clinicaltrials.gov, NCT04063852. This study is designed as a singlecentered, prospective, longitudinal cohort study with plans to follow participants for up to 24 months. Adult patients at the University of Michigan outpatient urology clinic presenting with multiple sclerosis and lower urinary tract symptoms (LUTS) including urinary frequency, urgency, incontinence refractory to two prior treatments who have elected to pursue percutaneous PTNS will be invited to participate (Table 2). Refractory symptoms are defined as bothersome LUTS that have not responded to at least two prior therapies including behavior modification, pharmacotherapy, pelvic floor physical therapy or bladder onabotulinum toxin. Full inclusion and exclusion criteria are listed in Table 2.

The PTNS procedure will be performed per the manufacturer's specifications using a Neuromodulation System (Urgent ${ }^{\odot} \mathrm{PC}$, Minnetonka, MN), as previously described [15]. Participants will undergo treatment for $30 \mathrm{~min}$, once per week for 12 weeks. After 12 weeks, those with more than $50 \%$ improvement in symptoms based on a visual analog scale, will be offered

Table 2 Inclusion and Exclusion criteria

Inclusion Criteria
Adults (age greater than or equal to 18 years old)
Diagnosis of Multiple Sclerosis
Lower urinary tract symptoms (urinary frequency, urgency and/or
incontinence)
Failed prior first and second line therapy (behavioral and
pharmacotherapy)
Electing for Posterior Tibial Nerve Stimulation therapy for urinary
symptoms.
Patients performing Intermittent Catheterization are Eligible
Exclusion Criteria
Age less than 18 years
Indwelling catheters (urethral or suprapubic)
currently pregnant or planning pregnancy
Unable to attend weekly office visits for PTNS
intravesical injection of onabotulinum toxin within 9 months
bladder stones
chanic findings of bladder outlet obstruction
History of:

maintenance PTNS sessions for 30 min every 28 days for a total of 24 months.

\section{Recruitment}

Participants will be recruited via a three-pronged approach. First, neurourology clinics at a tertiary care referral center will be screened for eligible patients. Eligible patients will be mailed letters regarding the study. Second, neurology and physical medicine and rehabilitation physicians at the same institution will be notified of the study. Finally, advertisements for the study will be posted on social media networks.

\section{Screening and enrollment}

Patients who meet inclusion criteria will be evaluated at baseline. Demographic and social information, and complete history and physical and neurologic evaluation with the Expanded Disability Status Scale (EDSS) will be evaluated at this time. Information from prior brain and spine MRI studies will be collected, if available. Participants will complete baseline questionnaires outlined below and summarized in Table 3.

\section{Follow-up and retention}

Efforts will be made to follow-up all patients through 24 months after time 0 (initiation of PTNS). This is inclusive of patients who do not have an improvement of symptoms with initial 12 weeks of PTNS and do not pursue maintenance PTNS. In order to promote follow-up and retention, participants will be offered the opportunity to complete questionnaires in person or electronically, via a Research Electronic Data Capture (REDCap) [25]. Furthermore, participants will be compensated at the time of return of a 3 -day voiding diary at times 0,12 , and 24 months.

Table 3 Outcome measurements and time points

\begin{tabular}{|c|c|c|c|c|}
\hline & \multicolumn{4}{|c|}{ Time Points (month) } \\
\hline & $0^{*}$ & $3^{* *}$ & 12 & 24 \\
\hline Demographic Intake Form & $x$ & & & \\
\hline \multicolumn{5}{|l|}{ LUTS Measurements: } \\
\hline 3 Day Voiding Diary & $x$ & $x$ & $x$ & $x$ \\
\hline AUA-SS & $x$ & $x$ & $x$ & $x$ \\
\hline M-ISI & $x$ & $x$ & $x$ & $x$ \\
\hline NBSS & $x$ & $x$ & $x$ & $x$ \\
\hline Visual Analog Scale & & $x$ & & \\
\hline Sexual Satisfaction Scale & $x$ & $x$ & $x$ & $x$ \\
\hline Bowel Control Scale & $x$ & $x$ & $x$ & $x$ \\
\hline SF-12 & $x$ & $x$ & $x$ & $x$ \\
\hline Expanded Disability Scale & $x$ & & $x$ & $x$ \\
\hline
\end{tabular}

*Time 0: start of PTNS therapy; **Time 3 months: end of weekly PTNS therapy; ${ }^{*}$ AUA-SS American Urological Association Symptom Score, M-ISI Michigan Incontinence Symptom Index, NBSS Neurogenic Bladder Symptom Score 


\section{Collection of study data}

Study data will be collected and managed using REDCap hosted at the University of Michigan [25]. REDCap is a secure, web-based application designed to support data capture for research studies [25].

\section{Study measurements}

Eligible persons will be evaluated at baseline (time of first PTNS treatment) and then at months 3, 12 and 24 from baseline (Table 3). Patients will be administered instruments assessing LUTS, HRQOL, Bowel and Sexual symptoms. Data collection instruments are summarized in Table 4.

Description of urinary symptom assessment tools For evaluation of LUTS the following instruments will be utilized: 1) 3-day voiding diary, 2) American Urological Association Symptom Score (AUA-SS), 3) Michigan Incontinence Symptom Index (M-ISI), and 4) Neurogenic Bladder Symptom Score. Voiding diaries are recommended in the routine evaluation of patients with neurogenic overactive bladder and the 3 day diary has been shown to be reliable in the evaluation of urge urinary incontinence [26, 27]. The AUA-SS was validated in 1992 and has been widely used in urologic literature including in the assessment of patients with MS. [11, 28, 29] Scores range from 0 to 35 with greater scores indicating more severe symptoms. The M-ISI is a 10 item questionnaire was developed and validated to discern between type of incontinence and the severity and bother caused by incontinence [30]. Greater scores indicate increased symptoms and the minimally important difference for urge urinary incontinence subdomain is 2 points [30]. The M-ISI has been utilized in prior literature in the context of MS. [11] The Neurogenic Bladder Symptom Score is a 22 item survey developed and validated for use in patients with spinal cord injury, MS and spina bifida [31]. The NBSS is a symptom scale which captures data regarding urinary incontinence, storage and voiding symptoms and complications of neurogenic bladder [31]. (Table 4).

Description of adjunct assessment tools Additional information regarding sexual activity and bowel symptoms will be assessed via selected tools which are part of the Multiple Sclerosis Quality of Life Index (MSQLI) [32, 33]. The MSQLI serves as a comprehensive assessment of HRQOL in patients with MS and consists of a Health Status Questionnaire (SF-36) and 9 subscales including bowel and sexual domains [32, 33]. For the purposes of this study the SF-12, Bowel Control Scale and Sexual Satisfaction Scale from the MSQLI are selectively utilized. The SF-12 is a 12-item version of the SF-36, the SF-12, was chosen to assess health status in order to decrease survey fatigue [34]. Literature has shown comparable results between SF-36 and SF-12 in the MS population [34, 35]. The Bowel Control Scale is a 5 item scale evaluating constipation, bowel accidents, bowel urgency and the impact of bowel symptoms of lifestyle on a 25 point scale with higher scores indicating greater bowel problems [33]. The Sexual Satisfaction Scale is a 5 -item index addressing overall sexual adjustment in patients with MS and was adapted by the MSQLI from the Sexual History Form, scores range from 4 to 24 with higher scores indicating greater problems with sexual satisfaction [32, 33]. Both the Sexual Satisfaction Scale and the Bowel Control Scale have been widely used and

Table 4 Description of data collection instruments

\begin{tabular}{|c|c|c|}
\hline & Name & Description \\
\hline \multirow[t]{4}{*}{$\begin{array}{l}\text { Urinary } \\
\text { Measures }\end{array}$} & 3-day Voiding Diary & $\begin{array}{l}\text { Patient completed } 3 \text { day assessment of fluid intake, output, incontinence episodes and pad } \\
\text { changes. }\end{array}$ \\
\hline & $\begin{array}{l}\text { American Urological Association } \\
\text { Symptom Score (AUA-SS) }\end{array}$ & $\begin{array}{l}\text { Validated symptom score for the evaluation of Lower Urinary Tract Symptoms in Benign } \\
\text { Prostatic Hyperplasia. Has been used in MS related research in the past. }\end{array}$ \\
\hline & $\begin{array}{l}\text { Michigan Incontinence Symptom } \\
\text { Score (M-ISI) }\end{array}$ & $\begin{array}{l}\text { Validated score developed to discern between type of incontinence and the severity and } \\
\text { bother caused by urinary incontinence }\end{array}$ \\
\hline & $\begin{array}{l}\text { Neurogenic Bladder Symptom } \\
\text { Score (NBSS) }\end{array}$ & $\begin{array}{l}\text { Objective and validated assessment of bladder symptoms specifically created for use in } \\
\text { patients with neurogenic bladder }\end{array}$ \\
\hline \multirow[t]{2}{*}{$\begin{array}{l}\text { Bowel and } \\
\text { Sexual Measures }\end{array}$} & Sexual Satisfaction Scale & $\begin{array}{l}\text { Validated, } 5 \text { item index addressing overall sexual adjustment in patients with MS and was } \\
\text { adapted by the MSQLI from the Sexual History Form, scores range from } 4 \text { to } 24 \text { with } \\
\text { higher scores indicating greater problems with sexual satisfaction. }\end{array}$ \\
\hline & Bowel Control Scale & $\begin{array}{l}\text { validated, } 5 \text { item scale evaluating constipation, bowel accidents, bowel urgency and the } \\
\text { impact of bowel symptoms of lifestyle on a } 25 \text { point scale with higher scores indicating } \\
\text { greater bowel problems }\end{array}$ \\
\hline General HRQOL & SF-12 & Validated 12 item quality of life survey for use in patients with chronic conditions. \\
\hline MS Impact & Expanded Disability Scale & Physician Completed assessment of impact of MS \\
\hline
\end{tabular}


validated as part of the MSQLI in the MS literature [32, 33]. (Table 4).

Description of neurologic disability assessment tools Neurologic impact of multiple sclerosis in participants will be evaluated using the Expanded Disability Status Scale (EDSS) at baseline and annually by a neurologist, resulting in 3 measurements over the 24-month study time frame [36]. Additionally, we will evaluate participants for change in Magnetic Resonance Imaging (MRI) over the 24-month period, including T2 lesion number and location. The EDSS was developed in the 1950s and has long been the standard for assessing MS progression in phase III clinical trials [36]. The EDSS assesses eight neurological exam functional systems; EDSS 0 means normal and 10, death. Aside from EDSS, MRI will provide objective measures of MS disease burden as reflected on T2 lesion load (Table 4).

\section{Study outcomes}

The primary outcome will be change in the median number of urinary frequency and urinary incontinence episodes on a 3-day voiding diary [37]. Secondary outcomes will be change in AUA symptom score (AUA-SS) and bothersome score, Michigan Incontinence Symptom Index (M-ISI), Neurogenic Bladder Symptom Score (NBSS), and from the Multiple Sclerosis Quality of Life Index (MSQLI) the Health Status Questionnaire (SF-12), Sexual Satisfaction Scale (SSS), and Bowel Control Scale (BCS) [28, 30-33].

\section{Sample size}

In this descriptive study, we aim to enroll at least 50 participants. While it is likely that the count of episodes in each of the time frames follows a Poisson distribution, the difference statistic could very well be expected to follow a normal distribution. If not, appropriate transformations would be applied to create an approximately normal distribution. Allowing for up to a $10 \%$ dropout rate, this sample size will provide a $95 \%$ chance to have a $95 \%$ confidence interval for our change statistic that is within $+/-1 / 3$ of a standard deviation. In other words, if we have an underlying standard deviation of 3 for the difference in counts, simulation results indicate that over 95\% of the time, the $95 \%$ confidence interval for the change statistic would fall within the mean $+/-1$. This will provide sufficient precision for our outcomes of interest.

\section{Statistical analysis}

Baseline descriptive demographic data will be presented for the entire cohort. The primary outcome of median number of urinary frequency and incontinence episodes on a 3-day voiding diary at 3,12 and 24 months will be compared to baseline for each patient using paired analysis. Secondary outcome measures including total AUA-SS, M-ISI, NBSS, SF-12, SSS and BCS scores at 3, 12 and 24 months will be compared to baseline for each patient using paired analysis. Continuous variables will be evaluated using paired t-test and categorical data will be analyzed using McNemar's test. Paired data will be evaluated using a 2-sided paired t-test. Median values will be analyzed using a Wilcoxon signed rank test. Statistical significance will be considered with $p<0.05$.

In order to assess for predictors of improvement of symptoms response to PTNS, planned subgroup analysis will be performed stratifying patients based on gender, EDSS score, and burden of disease on MRI. Furthermore, an interim analysis at evaluating outcomes at 3 and 12 months after PTNS is planned.

\section{Discussion}

The current literature regarding outcomes of PTNS in patients with MS who suffer from refractory lower urinary tract symptoms is favorable and is summarized in Table 1 [16-22, 38]. In 2009 Kabay published 3-month clinical outcomes in 19 patients showing significant decrease in mean overactive bladder questionnaire (OABV8) scores (15.7 vs 7.6, $p<0.05)$ [18]. Additionally they found a $40 \%$ complete response for urinary incontinence, and 58\% complete response for urinary frequency on bladder diaries [18]. In 2011, Gobbi reported 3 month results in 18 patients from a multicenter, open label trial which found that there was statistically significant improvement in frequency ( 9 vs 6 voids, $p=0.04$ ) and nocturia ( 3 vs 1 episodes, $p=0.002$ ), additionally there was a $70 \%$ treatment satisfaction and significant improvement in the patient perception of bladder condition (PPBC) and patient perception of intensity of urgency scales (PPIUS) as well as the King's Health Questionnaire (KHQ) [19]. The same group published long term outcomes (mean 24 months, range 15-41) which included variable maintenance PTNS every $2-4$ weeks, in 83 patients [20]. They reported $89 \%$ had greater than $50 \%$ improvement on the PPBC at 12 months and $82 \%$ had treatment satisfaction and improvement in PPBC at 24 months [20]. Of the 74 patients undergoing maintenance, the mean monthly treatment frequency was 1.8 sessions [20]. Most recently, Canbaz Kabay published 12-month outcomes in 29 patients, with 21 patients undergoing maintenance PTNS at variable intervals between 2 and 4 weeks [22]. Similar to prior studies, they found significant improvements in frequency, nocturia, urgency, and incontinence at 3, 6, 9 and 12 months of follow-up [22]. Furthermore, they found that there was significant improvement on International Consultation on Incontinence Questionnaire-Short Form (ICIQ-SF), OAB-V8 and OAB-q at 12 months [22]. 
Prior literature suggests that PTNS will improve LUTS in patients with MS, and that results may be sustained up to 24 months with maintenance therapy. However, the literature is limited in several ways. First, only two prior studies report outcomes beyond 3 months, in a total of 95 patients $[20,22]$. Next, the published maintenance schedules for PTNS in MS have varied between every 2-4 weeks, which makes it difficult to assess whether monthly maintenance PTNS is adequate for sustained efficacy [20, 22]. Furthermore, all prior studies have excluded patients with EDSS greater than 7 [16-22, 38]. Since patients with greater EDSS scores have increased disability, the impact of progressive MS patients who require assistive devices or wheelchairs for mobility is unknown. Finally, prior studies did not assess how early MS would respond to treatment. In light of ours and others' studies showing RRMS are associated with more bothersome urinary symptoms, it will interesting to see how the treatment will affect early MS with EDSS less than 2 and if disease progression impacts PTNS efficacy [7, 23].

Another significant knowledge gap is that health related quality of life (HRQOL) has been reported in only one study and no prior studies have reported on potential improvements in bowel and sexual function with PTNS [19]. Evaluating the impact on HRQOL provides data to guide clinicians and patients on whether the investment in PTNS is worthwhile for overall health. Assessment of bowel and sexual function outcomes may expand the applications for PTNS in this population. Finally, none of the previous PTNS studies have incorporated MRI measures. As another novel exploratory measure, our protocol will also incorporate retrospective MRI data of the participants, obtained for routine neurologic surveillance, before and after PTNS in order to evaluate whether brain and spinal cord lesion location, T2 lesion number and volume changes, and disease burden impact track with PTNS treatments.

\section{Conclusion}

This research protocol aims to expand on the existing literature regarding outcomes of PTNS in MS. Specifically, it will provide 24-month follow-up data on bladder, bowel, sexual and HRQOL outcomes. Further, it will be investigational data correlating EDSS and MRI results to PTNS, to evaluate whether lesion location or burden of disease is predictive of response to PTNS.

\section{Abbreviations}

AUA-SS: American Urological Association Symptom Score; BCS: Bowel Control Scale; CIS: Clinically isolated syndrome; EDSS: Expanded Disability Status Scale; HRQOL: Health related quality of life; KHQ: King's Health Questionnaire; LUTS: Lower urinary tract symptoms; M-ISI: Michigan Incontinence Symptom Index; MRI: Magnetic resonance imaging; MS: Multiple Sclerosis; MSQLI: Multiple Sclerosis Quality of Life Index; NBSS: Neurogenic Bladder Symptom Score; OAB: Overactive bladder; PPBC: Patient perception of bladder condition; PPIUS: Patient perception of intensity of urgency scales; PPMS: Primary progressive multiple sclerosis; PTNS: Posterior tibial nerve stimulation; RRMS: Relapsing remitting multiple
}

sclerosis; SF-12: Health Status Questionnaire; SPMS: Secondary progressive multiple sclerosis; SSS: Sexual Satisfaction Scale

\section{Acknowledgements}

Not applicable.

\section{Authors' contributions}

GL: developing research plan, writing manuscript, read and approved final manuscript. YMD: developing research plan, writing manuscript, read and approved final manuscript. PBR: developing research plan, read and approved final manuscript. QC: developing research plan, read and approved final manuscript. PG: developing research plan, read and approved final manuscript. RD: developing statistical analytic plan, read and approved final manuscript. YQ: developing statistical analytic plan, read and approved final manuscript. AC: developing research plan, read and approved final manuscript. JS: developing research plan, writing manuscript, read and approved final manuscript.

\section{Funding}

This study if funded by the 2018 Society of Urodynamics, Female Pelvic Medicine and Urogenital Reconstruction Research Foundation grant for Study of Neuromodulation, funded by Medtronic. The study funders did not have any authority over study design; collection, management, analysis, interpretation of data; writing the report; decision to submit the report for publication.

\section{Availability of data and materials}

Investigators will publish trial results. The datasets generated and/or analysed during the current study are not publicly available because they are identifiable but are available from the corresponding author on reasonable request.

\section{Ethics approval and consent to participate}

Institutional Review Board (Ethics approval) has been obtained for this study from the University of Michigan: HUM00153287. Participants will provide written informed consent prior to initiating in the study protocol.

Amendments to IRB will be declared at final publication of study and on the trial registry.

\section{Consent for publication}

Not applicable.

\section{Competing interests}

GL: no competing interests. YMD has served as a consultant and/or received grant support from: Acorda, Bayer Pharmaceutical, Biogen Idec, EMD Serono, Genzyme, Novartis, Questor, Chugai Pharmaceuticals, and Teva Neuroscience. Dr. Mao-Draayer is currently supported by grants from the NIH NIAID Autoimmune Center of Excellence: UM1-Al110557; NIH NINDS R01-NS080821, PCORI, Chugai, Novartis and Genzyme. PBR: no competing interests. QC: no competing interests. PG: no competing interests. RD: no competing interests. YQ: no competing interests. AC: reports personal fees from Wellspect, grants from Medtronic, outside of the submitted work. JS is supported by grants from the Department of Defense; received grant support from Ipsen, Uroplasty

\section{Author details}

'Department of Urology, University of Michigan, 1500 East Medical Drive, Taubman Center 3875, Ann Arbor, MI 48109, USA. ²Department of Neurology, University of Michigan, Ann Arbor, MI, USA.

Received: 2 August 2019 Accepted: 14 May 2020

Published online: 27 May 2020

\section{References}

1. Wallin MT, Culpepper WJ, Campbell JD, Nelson LM, Langer-Gould A, Marrie RA, et al. The prevalence of MS in the United States: a population-based estimate using health claims data. Neurology. 2019;92(10):e1029-40.

2. Types of MS. National Multiple Sclerosis Society. Available from: https:// www.nationalmssociety.org/What-is-MS/Types-of-MS. Cited 2019 May 20.

3. Compston A, Coles A. Multiple sclerosis. Lancet. 2002;359(9313):1221-31. 
4. Koch M, Kingwell E, Rieckmann P, Tremlett H, UBC MS. Clinic neurologists. The natural history of secondary progressive multiple sclerosis. J Neurol Neurosurg Psychiatry. 2010;81(9):1039-43.

5. Lublin FD, Reingold SC, Cohen JA, Cutter GR, Sørensen PS, Thompson AJ, et al. Defining the clinical course of multiple sclerosis: the 2013 revisions. Neurology. 2014;83(3):278-86.

6. Khalaf KM, Coyne KS, Globe DR, Armstrong EP, Malone DC, Burks J. Lower urinary tract symptom prevalence and management among patients with multiple sclerosis. Int J MS Care. 2015;17(1):14-25.

7. Di Filippo M, Proietti S, Gaetani L, Gubbiotti M, Di Gregorio M, Eusebi P, et al. Lower urinary tract symptoms and urodynamic dysfunction in clinically isolated syndromes suggestive of multiple sclerosis. Eur J Neurol. 2014;21(4):648-53.

8. Stoffel JT. Contemporary management of the neurogenic bladder for multiple sclerosis patients. Urol Clin North Am. 2010;37(4):547-57.

9. Overactive Bladder $(\mathrm{OAB})$ Guideline - American Urological Association. Available from: https://www.auanet.org/guidelines/overactive-bladder-(oab)guideline. Cited 2019 May 15

10. Gormley EA, Lightner DJ, Burgio KL, Chai TC, Clemens JQ, Culkin DJ, et al. Diagnosis and treatment of overactive bladder (non-neurogenic) in adults: AUA/SUFU guideline. J Urol. 2012;188(6 Suppl):2455-63.

11. Dray E, Cameron AP, Clemens JQ, Qin Y, Covalschi D, Stoffel J. Does postvoid residual volume predict worsening urological symptoms in patients with multiple sclerosis? J Urol. 2018;200(4):868-74.

12. Ginsberg D, Gousse A, Keppenne V, Sievert K-D, Thompson C, Lam W, et al. Phase 3 efficacy and tolerability study of onabotulinumtoxinA for urinary incontinence from neurogenic detrusor overactivity. J Urol. 2012;187(6): 2131-9.

13. Puccini F, Bhide A, Elneil S, Digesu GA. Sacral Neuromodulation: an effective treatment for lower urinary tract symptoms in multiple sclerosis. Obstet Gynecol Surv. 2016;71(7):401.

14. Information for Prescribers. Medtronic; 2018. Available from: http://manuals. medtronic.com/content/dam/emanuals/neuro/M976705A_a_001_view.pdf.

15. Peters KM, Carrico DJ, Perez-Marrero RA, Khan AU, Wooldridge LS, Davis GL, et al. Randomized trial of percutaneous tibial nerve stimulation versus sham efficacy in the treatment of overactive bladder syndrome: results from the SUmiT trial. J Urol. 2010;183(4):1438-43.

16. Fjorback MV, van Rey FS, van der Pal F, Rijkhoff NJM, Petersen T, Heesakkers JP. Acute urodynamic effects of posterior tibial nerve stimulation on neurogenic detrusor overactivity in patients with MS. Eur Urol. 2007;51(2): 464-70 discussion 471-2

17. Kabay SC, Yucel M, Kabay S. Acute effect of posterior tibial nerve stimulation on neurogenic detrusor overactivity in patients with multiple sclerosis: urodynamic study. Urology. 2008;71(4):641-5.

18. Kabay S, Kabay SC, Yucel M, Ozden H, Yilmaz Z, Aras O, et al. The clinical and urodynamic results of a 3-month percutaneous posterior tibial nerve stimulation treatment in patients with multiple sclerosis-related neurogenic bladder dysfunction. Neurourol Urodyn. 2009;28(8):964-8.

19. Gobbi C, Digesu GA, Khullar V, El Neil S, Caccia G, Zecca C. Percutaneous posterior tibial nerve stimulation as an effective treatment of refractory lower urinary tract symptoms in patients with multiple sclerosis: preliminary data from a multicentre, prospective, open label trial. Mult Scler. 2011; 17(12):1514-9.

20. Zecca C, Digesu GA, Robshaw P, Singh A, Elneil S, Gobbi C. Maintenance percutaneous posterior nerve stimulation for refractory lower urinary tract symptoms in patients with multiple sclerosis: an open label, multicenter, prospective study. J Urol. 2014;191(3):697-702.

21. Zecca C, Digesu GA, Robshaw P, Puccini F, Khullar V, Tubaro A, et al. Motor and sensory responses after percutaneous tibial nerve stimulation in multiple sclerosis patients with lower urinary tract symptoms treated in daily practice. Eur J Neurol. 2014;21(3):506-11.

22. Canbaz Kabay S, Kabay S, Mestan E, Cetiner M, Ayas S, Sevim M, et al. Long term sustained therapeutic effects of percutaneous posterior tibial nerve stimulation treatment of neurogenic overactive bladder in multiple sclerosis patients: 12-months results. Neurourol Urodyn. 2017;36(1):104-10.

23. Cox L, Cameron AP, Wittman D, Papin JE, Stoffel JT. Analysis Of Urinary Symptoms And Urodynamic Findings In Multiple Sclerosis Patients By Gender And Disease Subtype. J Neurol Neurobiol. 2015; 1(2). Available from: https://www.researchgate.net/publication/276961511_Analysis_Of_Urinary_ Symptoms_And_Urodynamic_Findings_In_Multiple_Sclerosis_Patients_By_ Gender_And_Disease_Subtype. Cited 2019 Apr 8.
24. Sanagapalli S, Neilan L, Lo JYT, Anandan L, Liwanag J, Raeburn A, et al. Efficacy of percutaneous posterior Tibial nerve stimulation for the Management of Fecal Incontinence in multiple sclerosis: a pilot study: PTNS for fecal incontinence in multiple sclerosis. Neuromodulation. 2018;21(7): $682-7$.

25. Harris PA, Taylor R, Thielke R, Payne J, Gonzalez N, Conde JG. Research electronic data capture (REDCap)--a metadata-driven methodology and workflow process for providing translational research informatics support. J Biomed Inform. 2009;42(2):377-81.

26. Groen J, Pannek J, Castro Diaz D, Del Popolo G, Gross T, Hamid R, et al. Summary of European Association of Urology (EAU) guidelines on Neurourology. Eur Urol. 2016;69(2):324-33.

27. Bright E, Drake MJ, Abrams P. Urinary diaries: evidence for the development and validation of diary content, format, and duration. Neurourol Urodyn. 2011;30(3):348-52

28. Barry MJ, Fowler FJ Jr, O'Leary MP, Bruskewitz RC, Holtgrewe HL, Mebust WK, et al. The American urological association symptom index for benign prostatic hyperplasia. The measurement Committee of the American Urological Association. J Urol. 1992;148(5):1549-57 discussion 1564.

29. Weissbart SJ, Pechersky D, Malykhina A, Bavaria T, Parrillo L, Arya LA, et al. The impact of pontine disease on lower urinary tract symptoms in patients with multiple sclerosis. Neurourol Urodyn. 2017:36(2):453-6.

30. Suskind AM, Dunn RL, Morgan DM, DeLancey JOL, McGuire EJ, Wei JT. The Michigan incontinence symptom index (M-ISI): a clinical measure for type, severity, and bother related to urinary incontinence. Neurourol Urodyn. 2014;33(7):1128-34.

31. Welk B, Morrow S, Madarasz W, Baverstock R, Macnab J, Sequeira K. The validity and reliability of the neurogenic bladder symptom score. J Urol. 2014;192(2):452-7.

32. Marrie RA, Miller DM, Chelune GJ, Cohen JA. Validity and reliability of the MSQLI in cognitively impaired patients with multiple sclerosis. Mult Scler. 2003;9(6):621-6.

33. Guidebook - MSQLI Manual and Forms (.pdf). Available from: https://www. nationalmssociety.org/NationalMSSociety/media/MSNationalFiles/Brochures/ MSQLI_A-User-s-Manual.pdf.

34. Ware J Jr, Kosinski M, Keller SD. A 12-item short-form health survey: construction of scales and preliminary tests of reliability and validity. Med Care. 1996;34(3):220-33.

35. Nortvedt MW, Riise T, Myhr KM, Nyland HI. Performance of the SF-36, SF-12, and RAND-36 summary scales in a multiple sclerosis population. Med Care. 2000;38(10):1022-8.

36. Kurtzke JF. Rating neurologic impairment in multiple sclerosis: an expanded disability status scale (EDSS). Neurology. 1983;33(11):1444-52.

37. Society of Urodynamics, Female Pelvic Medicine and Urogenital Reconstruction 3 day voiding Diary. SUFU 3 day voiding diary. Available from: https://sufuorg.com/docs/guidelines/sufu-voiding-diary-faq.aspx. Cited 2019 Apr 5

38. de Sèze M, Raibaut P, Gallien P, Even-Schneider A, Denys P, Bonniaud V et al. Transcutaneous posterior tibial nerve stimulation for treatment of the overactive bladder syndrome in multiple sclerosis: results of a multicenter prospective study. Neurourol Urodyn. 2011;30(3):306-11.

\section{Publisher's Note}

Springer Nature remains neutral with regard to jurisdictional claims in published maps and institutional affiliations.

Ready to submit your research? Choose BMC and benefit from:

- fast, convenient online submission

- thorough peer review by experienced researchers in your field

- rapid publication on acceptance

- support for research data, including large and complex data types

- gold Open Access which fosters wider collaboration and increased citations

- maximum visibility for your research: over $100 \mathrm{M}$ website views per year

At $\mathrm{BMC}$, research is always in progress.

Learn more biomedcentral.com/submissions 